\title{
Increased Removal Efficiency of Lead (Pb) in used Lubricating Oil with Acid Activated Clay
}

\author{
Firsta Hilwa and Setyo Sarwanto Moersidik \\ Department of Civil Engineering, Faculty of Environmental Engineering, Universitas Indonesia, \\ 16424 Depok, West Java, Indonesia, +62217270029, ssarwanto@eng.ui.ac.id
}

\begin{abstract}
Used lubricating oil is one of waste categorized as hazardous and toxic waste. It contains heavy metal and one of them is lead. The existence of lead is due to when the engine is working, so that, the engine is wearing and lead metal is released to the lubricant. Removing lead from used lubricating oil can be done by using natural clay (bleaching Earth) as adsorbent. In this study, the clay was activated by using sulfuric acid $\left(\mathrm{H}_{2} \mathrm{SO}_{4}\right)$ with $1,1.5$ and $2 \mathrm{M}$ concentration variation. By using sulfuric acid, the percentage of montmorillonite mineral increased up to $68 \%$ and the surface area expanded up to $62.9 \mathrm{~m}^{2} / \mathrm{g}$. Activation is also seen to increase the adsorbensi, power and shorten the contact time. From the experimental results, it is found that optimum adsorption conditions occured at activation with concentration of $1.5 \mathrm{M}$ and with $30 \mathrm{~min}$ adsorption time. Under these conditions, concentration variation of adsorbent with concentration of $20,40,60,80$ and $100 \mathrm{~g} / \mathrm{L}$ were observed. With this variation, the result shows optimum concentration of $20 \mathrm{~g} / \mathrm{L}$.
\end{abstract}

Key words: Adsorption, acid activation, lead, natural clay (bleaching Earth), used lubrican, mineral

\section{INTRODUCTION}

Used lubricant is one of the liquid wastes that is categorized as a hazardous and toxic waste. Used lubricants from motor vehicles engines and machine in industry are usually contain toxins and are contaminated with hazardous substances such as cadmium, Polycyclic Aromatic Hydrocarbons (PAHs), zinc, arsenic, Polychlorinated Biphenyls (PCBs) and other metals, one of those is lead $(\mathrm{Pb})$ (Udonne and Onwuma, 2014). Although, it contains hazardous materials, used lubricants still have the potential to become a base oil with a purification process.

There are several methods used for the purification process of used lubricants including distillation, extraction and adsorption processes. Of the three methods, the simplest method to do is the adsorption process. Purification of used lubricants using an adsorption process can be carried out with several types of adsorbents such as activated carbon, zeolite, clay soil and other adsorbents. For economic considerations, clay adsorbents are recommended adsorbents because they are natural ingredients that are easy to obtain.
Purification of used lubricants using clay adsorption is now quite a lot used on an industrial scale. In general, the use of clay or often referred to as bleaching Earth, in the process of oil purification on an industrial scale is $10-30 \%$ of the volume of used lubricant waste (Usman et al., 2012). Clay which has absorbed the pollutant will become a new waste for the environment with a considerable amount. To solve the problem. One way that can be done is to reduce the amount of clay needed by activating the adsorbent which can be done physically or chemically.

Physical activation is usually done by heating the adsorbent at temperatures up to $700^{\circ} \mathrm{C}$. The heating process at a low temperature between $100-200^{\circ} \mathrm{C}$ will evaporate the water molecules between the layer of adsorbent. Whereas for heating at a higher temperature of $500-700^{\circ} \mathrm{C}$ causes the process of water molecules to come out of the crystal circuit, so that, the adjacent $\mathrm{OH}$ group releases one water molecule (Prasetya, 2004).

For chemical activation is carried out by the addition of a chemical. One type of chemical activation is using acid. The acid used as a chemical

Corresponding Author: Setyo Sarwanto Moersidik, Department of Civil Engineering, Faculty of Environmental Engineering, Universitas Indonesia, 16424 Depok, West Java, Indonesia, +62217270029, ssarwanto@eng.ui.ac.id 
for activation in general is strong acid. In this study, the acid used as activating agent was sulfuric acid $\left(\mathrm{H}_{2} \mathrm{SO}_{4}\right)$. Addition of sulfuric acid to the clay adsorbent can increase the surface area and porosity of clay adsorbents, so that, the adsorption power of the clay gets bigger (Kumar et al., 1995). Increasing the adsorption power of the clay is due to the activating agent functioning to remove the inherent impurities and cover the adsorbent pores by oxidizing the adsorbent (Shofa, 2012).

Problem statement: Used lubricating oil purification by the adsorption process using clay as an adsorbent will have by products in the form of adsorbent waste. With the use of a lot of clay to remove lead metal, more waste will be produced. In addition, the energy needed to prepare clay to become adsorbent also becomes more numerous. Therefore, a study is needed to minimize the amount of adsorbent used to remove lead from used lubricanting oil.

The aim of research: This study conducted research to provide recommendations process of used lubricating oil purification with minimal resources and environmentally friendly.

\section{MATERIALS AND METHODS}

The clay adsorbent used in this study was originating from Sukabumi, West Java, Indonesia. The used lubricant waste was taken from one of the workshops in South Jakarta, Indonesia.

Clay preparation: Clay preparation was done by heating at a temperature of $260-300^{\circ} \mathrm{C}$ to remove the moisture content in the clay. After clay was dried, then mashed to 200 mesh.

Acid activation: Activation was carried out by adding sulfuric acid $\left(\mathrm{H}_{2} \mathrm{SO}_{4}\right)$ with variations in acid concentrations of $1,1.5$ and $2 \mathrm{M}$. The acid mixed into the clay was $5 \mathrm{~mL}$ for every $1 \mathrm{~g}$ of clay into glass beaker (Usman et al., 2012). Then the activation process was carried out by stirring the acid with clay at a speed of $200 \mathrm{rpm}$ for $60 \mathrm{~min}$ (Wulan Sari et al., 2016). After stirring then $\mathrm{H}_{2} \mathrm{SO}_{4}$ acid is removed and then the clay is washed using distilled water until the $\mathrm{H}_{2} \mathrm{SO}_{4}$ solution is lost. After the washing process, the clay is filtered with filter paper to separate water from clay.
After filtering using filter paper to separate water, the next step is to reheat at $105^{\circ} \mathrm{C}$ (in the oven) until there is no moisture content. After reaching room temperature, the sample is refined to 200 mesh.

Adsorption process: Adsorption in this study was divided into two stages. For stage 1, the adsorption process is intended to find the optimum adsorption time and optimum $\mathrm{H}_{2} \mathrm{SO}_{4}$ concentration used for clay activation. For stage 1 , there are two variations, molarity variation of $\mathrm{H}_{2} \mathrm{SO}_{4}(1,1.5$ and $2 \mathrm{M})$ and adsorption time variation $(30,60,180$ and $300 \mathrm{~min})$. The adsorption process was carried out at a heating temperature of $120^{\circ} \mathrm{C}$ and a stirring speed of $435 \mathrm{rpm}$. In this study, the volume of used lubricant that is used at one adsorption process was $300 \mathrm{~mL}$ (preheated at $120^{\circ} \mathrm{C}$ for $5 \mathrm{~min}$ ) and after adsorption is carried precipitation for $24 \mathrm{~h}$ and then decanted. For adsorption at stage 1 the concentration of clay $80 \mathrm{~g} / \mathrm{L}$.

For the second phase adsorption process is performed to find the optimum value of the concentration of clay in the adsorption process. This process is carried out with various concentrations of $20,40,60,80,100$ and $120 \mathrm{~g} / \mathrm{L}$. The adsorption time is determined from the optimum time obtained from the phase 1 adsorption as well as the optimum acid concentration used in this stage 2 .

Clay characterization: In determining the changes in the characteristics of clay which can affect the adsorption process, the surface area and mineral composition of the clay were tested. For the surface area, Brunauer-Emmet-Teller (BET) test was carried out and for the mineral composition X-Ray Diffractometer (XRD) was tested. The XRD data obtained from the test results are qualitative, so that, processing with MAUD Software is needed to obtain quantitative data.

Lubricant characterization: In finding out the characteristics of used lubricants before and after the adsorption process, the following tests were carried out.

Table 1: Analysis methods of lubricant characteristics

\begin{tabular}{ll}
\hline Characteristic & Analysis methods \\
\hline Kinematic viscocity $40^{\circ} \mathrm{C}(\mathrm{cst})$ & ASTM D445 \\
Flash point $\left({ }^{\circ} \mathrm{C}\right)$ & ASTM D92 \\
Pour point $\left({ }^{\circ} \mathrm{C}\right)$ & ASTM D97 \\
Specific gravity $\left(\mathrm{g} / \mathrm{cm}^{3}\right)$ & Density meter \\
Total base number $(\mathrm{mg} / \mathrm{KOH}$ g) & ASTM D95-13 \\
Moisture content $(\%)$ & ASTM D95-13 \\
Lead concentration & X-ray fluorescence spectometry \\
\hline
\end{tabular}




\section{RESULTS AND DISCUSSION}

Figure 1 showed that there was an increase in the surface area of the clay after activation with acid. On activation using $\mathrm{H}_{2} \mathrm{SO}_{4}$ concentration of $1 \mathrm{M}$, the surface area of clay increased from $54.8-62.9 \mathrm{~m}^{2} / \mathrm{g}$. This increase in surface area is due to the acid can dissolve all impurities contained in the adsorbent pores (Salem et al., 2015a, b). The impurities that are usually removed using acid are metal oxides found on the surface of the clay used as adsorbent (Ngapa, 2017).

The activation process with acids can also affect the mineral composition in clay. Figure 2 shows changes in the composition of minerals contained in the Sukabumi clay before and after the activation process. From the analysis using the MAUD Software it is known that the minerals contained in the clay are montmorillonite, clipnoptilolite and quartz. In Fig. 2 the activation process generally increases the percentage of montmorillonite minerals in clay. This increase is very good because montmorillonite is a mineral that is very easy to bind lead metal pollutants $(\mathrm{Pb})$ in the adsorption process.

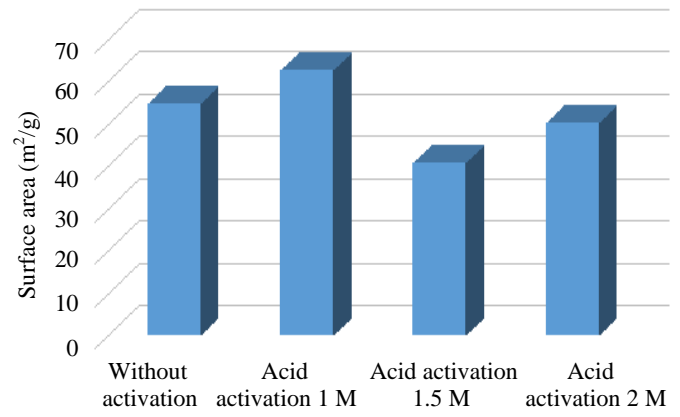

Fig. 1: Surface area of the activation result
In the acid activation process, the use of 1 , 1.5 and $2 \mathrm{M} \mathrm{H}_{2} \mathrm{SO}_{4}$ increased the percentage of montmorillonite which initially was $53.53-62 \%, 64.47$ and $68.44 \%$, respectively.

The activation process with acid itself gives $\mathrm{H}^{+}$ions which can replace the cations contained in the clay. In the event of contact with acid most of the $\mathrm{SiO}_{4}$ bond will not change (still intact) while $\mathrm{Al}_{3}{ }^{+}$and $\mathrm{Mg}_{2}{ }^{+}$ions will come out from the octahedral bond. This decomposition of the octahedral layer is strongly related to the resistance of compounds to acidic influences. With the change in acidity in clay minerals, from previous studies it has been known that acid activation and continued heating will increase adsorption capacity (Salem et al., 2015a, b). After knowing the effect of the acid activation process on the physical and chemical characteristics of the clay, the adsorption process was then carried out to determine the lead removal with variations in acid molarity and adsorption time. The use of non-activated clays can remove lead metal in the used lubrication oil by $68 \%$ within $300 \mathrm{~min}$ (Fig. 3). After the clay is activated with acid there is an increase in the percentage of lead removal in shorter contact time.

From the Fig. 3 of adsorption result by using acid activated clay on the graph, the optimum lead metal removal occurred at adsorption by using activated clay 1.5 and $2 \mathrm{M}$ within $30 \mathrm{~min}$ of adsorption time. The $30 \mathrm{~min}$ reaction time is chosen considering the equilibrium time of the adsorption process by using acid activated clays. A $30 \mathrm{~min}$ time is also chosen for energy efficiency in the adsorption process. Considering the raw material, the concentration of acid selected at the adsorption process is $1.5 \mathrm{M}$ of acid, since, the lead removal at $30 \mathrm{~min}$ with the activated clay of the concentration reached $100 \%$.

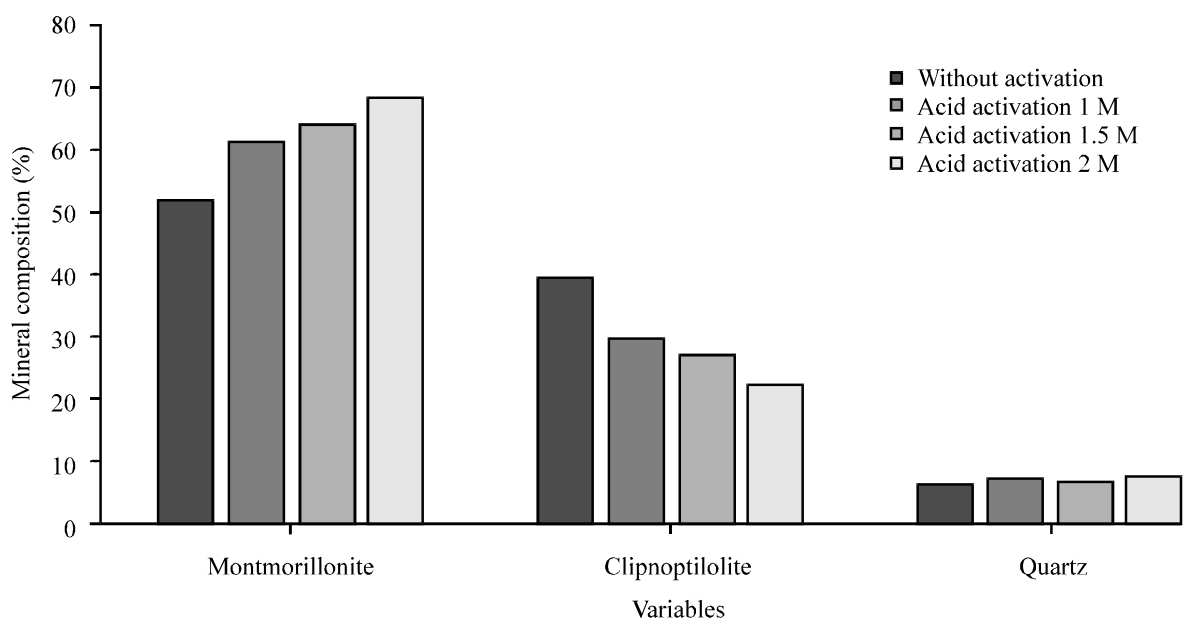

Fig. 2: Mineral composition resulted from acid activation 


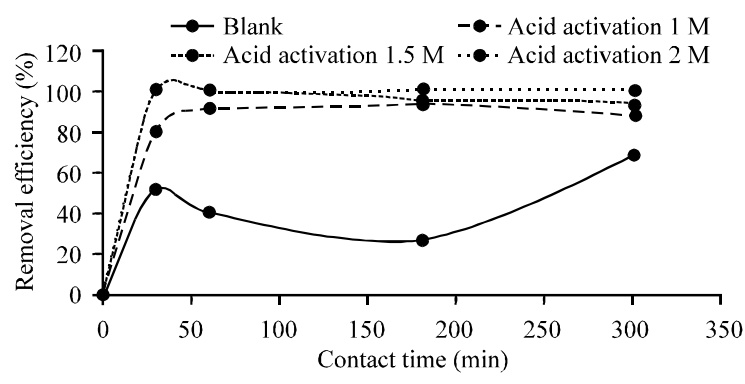

Fig. 3: Removal efficiency of lead after adsorption process with clay activated by acid

The increase in $\mathrm{Pb}$ removal using acid-activated clay is in accordance to previous research which stated that activation using acid which is an activating agent chemical solution can oxidize the adsorbent to remove inherent impurities and cover the surface of the adsorbent, so that, pores will be formed to increase adsorption power. With uplift and loss impurities of clay adsorbent can increase the surface area and porosity of the clay adsorbent, so that, the adsorption power of the clay gets bigger (Kumar et al., 1995). In addition, this increase can also be associated with changes in mineral composition in clay after the activation process. According to previous research, montmorillonite mineral is a good adsorbent for metal ions, especially, at low $\mathrm{pH}$ (Jaslin, 2005). Therefore, it can be said that the greater the percentage of montmorillonite minerals, the higher the increase of metal ions adsorption.

From the first stage adsorption results, it is known that the optimum lead adsorption conditions occur in $1.5 \mathrm{M}$ acid activated clay and $30 \mathrm{~min}$ adsorption time. Therefore, for the second stage of the adsorption process, the adsorption is carried out under optimum conditions with variations in the concentration of adsorbent $(20,40$, $60,80,100,120 \mathrm{~g} / \mathrm{L}$ )

From the results that can be seen in Fig. 4, the adsorption process with an adsorbent concentration of $20 \mathrm{~g} / \mathrm{L}$ removed lead to $100 \%$ and the lead removal is constant to an adsorbent concentration of $120 \mathrm{~g} / \mathrm{L}$.

The increase of adsorbent concentration will be followed by the increase of clay active sites that will bind the positive charge of lead in waste lubricant oil. However, as can be seen in lead removal in the graph, the addition of adsorbent concentration gradually does not affect a notable increase removal percentage. This is possibly caused when the clay was added to a certain concentration, almost all of lead has been bound to clay active site (Pohan et al., 2016).

The adsorption results indicate that clay activation with acid has potential to reduce the amount of clay concentration required in the adsorption process which

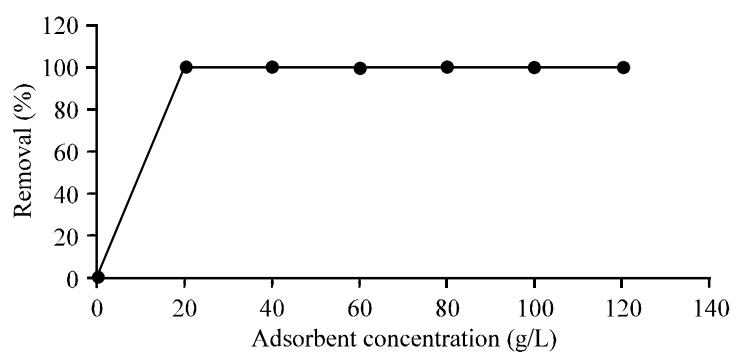

Fig. 4: Removal efficiency of lead after adsorption process with clay activated by acid (Variation of concentration)

Table 2: Result of characterization of used lubric ant after adsorptions

\begin{tabular}{lrrc}
\hline Characteristics & & & $\begin{array}{c}\text { Recycled oil } \\
\text { (Acid activation) }\end{array}$ \\
Kinematic viscocity $40^{\circ} \mathrm{C}(\mathrm{cst})$ & 67.23 & 51.44 & 49.11 \\
Flash point $\left({ }^{\circ} \mathrm{C}\right)$ & 238 & 196 & 212 \\
Pour point $\left({ }^{\circ} \mathrm{C}\right)$ & -39 & $<-36$ & $<-36$ \\
Specific gravity $\left(\mathrm{g} / \mathrm{cm}^{3}\right)$ & 0.853 & 0.846 & 0.853 \\
Total base number $(\mathrm{mg} / \mathrm{KOH} \mathrm{g})$ & 6.43 & 5.82 & 6.9 \\
Moisture content $(\%)$ & 0 & $<0.5$ & $<0.5$ \\
\hline
\end{tabular}

was up to $20 \mathrm{~g} / \mathrm{L}$. As the clay concentration getting smaller, the fewer by-products which were known as used bleaching earth cake and ash will be produced.

With an optimum concentration of $20 \mathrm{~g} / \mathrm{L}$, the refined lubricant can be seen in Table 2. From these results the used lubricant that has been recycled using activated clay is still physically and chemically sufficient to meet some new lubricant standards. However, it is required to add additives to obtain the desired conditions.

Table 2 show that, kinematic viscosity of lubricant adsorption results using acid activated clay was decreased. The decrease in the value of kinematic viscosity is due to the presence of sulfuric acid in the clay. According to previous research, sulfuric acid can reduce kinematic viscosity values in treatment lubricants (Mara and Kurniawan, 2015). For the flash point value shows a good influence. The flash point value of the lubricant from the adsorption using acid activated clay increased from $196^{\circ} \mathrm{C}$ (used oil) to $212^{\circ} \mathrm{C}$. The values of specific gravity and Total Base Number (TBN) also showed an increase of 0.853 and $6.9 \mathrm{mg} / \mathrm{KOH}$ g. TBN value increase is very good for lubricant performance because the Total Base Number (TBN) can play a role in preventing corrosion on the lubricated surface of the engine (Suhartini and Rahmawati, 2009). Whereas for pour point and moisture content values of the adsorption results lubricants are $<-36^{\circ} \mathrm{C}$ and $<0.5$. The value of the pour point and moisture content cannot be determined because of detection limit of the device. Therefore, no further analysis can be carried out. 


\section{CONCLUSION}

This study shows that the activation of clays by using acid can increase the removal of lead $(\mathrm{Pb})$ metal (almost eliminating) in used lubricants by the adsorption process. The optimum condition of this adsorption process was $1.5 \mathrm{M}$ acid concentration, $30 \mathrm{~min}$ adsorption time and $20 \mathrm{~g} / \mathrm{L}$ adsorption concentration. For the characteristics of adsorption lubricants such as flash point, pour point, specific gravity, TBN and moisture content were almost identical to the characteristics of new lubricants. However, the kinematic viscosity value was still low, so that, additional additives are needed. Therefore, overall this study specified that acid activated bleaching Earth can be an alternative to treat hazardous waste such as used lubricants to be used oil.

\section{ACKNOWLEDGEMENTS}

Facilities provided by Research and Development Centre for Oil and Gas Technology Indonesia (LEMIGAS) and financial support by PITTA University of Indonesia with contract number 2530/UN2.R3.1/HKP.05.00/2018.

\section{REFERENCES}

Jaslin, I., 2005. [Understand the adsorption of metal ion processes by the mineral clay]. Proceedings of the National Seminar on Research, Education and Application of Mathematics and Natural Sciences (MIPA 2005), February 8, 2005, FMIPA-UNY, Yogyakarta, Indonesia, pp: 10-19 (In Indonesian).

Kumar, P., R.V. Jasra and T.S.G. Bhat, 1995. Evolution of porosity and surface acidity on montmorillonite clay. Ind. Eng. Chem. Res., 34: 1440-1 448.

Mara, M. and A. Kurniawan, 2015. [Analysis of use of used lubrication oil with method acid and clay (In Indonesian)]. Dyn. Mech. Eng., 5: 106-112.
Ngapa, Y.D., 2017. [Study of acid-basic influence in zeolite activation and the characterization as adsorben blue dyes metilen (In Indonesian)]. JKPK. Chem. J. Chem. Educ., 2: 90-96.

Pohan, M.S.A., S. Sutarno and S. Suyanta, 2016. [Adsorption-desorption study of phosphate anions on CTAB-modified zeolites (In Indonesian)]. J. Sci. Res., 18: 123-135.

Prasetya, W., 2004. Effect of Phosphoric Acid treatment and characterization of na-montmorillonnit clay characteristics. MSc Thesis, State University of Semarang, Semarang, Central Java, Indonesia.

Salem, S., A. Salem and A.A. Babaei, 2015a. Application of Iranian nano-porous Ca-bentonite for recovery of waste lubricant oil by distillation and adsorption techniques. J. Ind. Eng. Chem., 23: 154-162.

Salem, S., A. Salem and A.A. Babaei, 2015b. Preparation and characterization of nano porous bentonite for regeneration of semi-treated waste engine oil: Applied aspects for enhanced recovery. Chem. Eng. J., 260: 368-376.

Shofa, 2012. Making active carbon made from sugar cane raw by activating potassium hydroxide. BA Thesis, University of Indonesia, Depok, Indonesia.

Suhartini, M. and R. Rahmawati, 2009. [Addition of natural rubber latex coopolymer radiation and improvement of viscosity index oil printed synthetic lubricants (In Indonesian)]. Indonesian Mater. Sci. J., 11: 10-14.

Udonne, J.D. and H.O. Onwuma, 2014. A study of the effects of waste lubricating oil on the physical/chemical properties of soil and the possible remedies. J. Pet. Gas Eng., 5: 9-14.

Usman, M.A., V.I. Ekwueme, T.O. Alaje and A.O. Mohammed, 2012. Characterization, acid activation and bleaching performance of Ibeshe clay, Lagos, Nigeria. Intl. Scholarly Res. Netw. Ceram., 2012: 1-5.

Wulan Sari, T.I., M. Muhsin and H. Wijayanti, 2016. [The effect of activation method on the ability of kaolin as the Garuda ( $\mathrm{Fe}$ ) water well of garuda water (In Indonesian)]. UNLAM. Convers. J., 1: 20-25. 